\title{
The Effect of Parental Separation on Young Adults' Political and Civic Participation
}

\author{
Marieke Voorpostel $\cdot$ Hilde Coffé
}

Accepted: 12 September 2014/Published online: 26 September 2014

(C) Springer Science+Business Media Dordrecht 2014

\begin{abstract}
Whereas an extensive literature exists on the effect of parental separation on young adults' health, well-being and educational attainment, relatively little is known about its effect on young adults' political and civic engagement. The current paper aims to remedy this deficiency and explore to what extent parental separation affects young adults' likelihood to vote and volunteer. Taking insights from the social learning and parental status theories, we argue that because of separated parents' overall lower levels of political and civic engagement as well as socioeconomic status compared with parents who are living together, young adults with separated parents will be less likely to engage in political and civic life compared with those whose parents are living together. Using data from the Swiss Household Panel Survey (1999-2009), our analyses reveal in line with our expectations that parental separation has a negative effect on young adults' voting and volunteering patterns. Supporting the social learning theory, this negative effect of parental divorce or separation can be partly explained by the lower levels of political and civic engagement among separated parents compared with parents who are living together.
\end{abstract}

Keywords Separation · Divorce $\cdot$ Young adults · Voting frequency · Volunteering

\section{Introduction}

The understanding that parents are prime agents of political and civic socialization has occupied an important place in the socialization literature, and empirical evidence suggests

\footnotetext{
M. Voorpostel ( $\bowtie)$

FORS, University of Lausanne, Lausanne, Switzerland

e-mail: marieke.voorpostel@fors.unil.ch

H. Coffé

Political Science and International Relations Programme, Victoria University of Wellington,

Wellington, New Zealand

e-mail: hilde.coffe@vuw.ac.nz
} 
that parents play a prominent role in explaining young people's political and civic attitudes and behaviour (Coffé and Voorpostel 2010; Flanagan et al. 1998; Flanagan and Sherrod 1998; Jennings et al. 2009; Kroh 2011; Nieuwbeerta and Wittebrood 1995; Perry and Associates 2002; Verba et al. 2005; Wernli 2007). Discussions at home about politics, and parental examples of voting and volunteering, relate positively to offspring's civic engagement (Andolina et al. 2003). Most research studying the link between parents' political and civic engagement and their children's engagement, however, takes a traditional approach to the family. It focuses on 'traditional families', defined as married couples with children, and pays little attention to how new family forms and constellations may influence young adults' interest in and opportunities for political and civic participation. Yet, a growing number of adolescents are raised in 'non-traditional' families, as indicated-among other things-by increasing divorce rates.

In this paper, we start from these changes in family structure and aim to provide a systematic analysis of the effect of parental separation on young adults' political and civic participation. Although ample research reveals associations between parental separation and children's health and wellbeing (Amato 2000; Kalmijn 2010; Amato and James 2010), educational attainment (Amato 2000; Amato and Keith 1991; Amato and James 2010) or psychological adjustment (Gahler and Garriga 2012; Amato and James 2010), how parental separation influences young adults' levels of civic and political participation has hardly received any research attention (but see, Dolan 1995; Langton 1969; Sandell and Plutzer 2005; Prokic and Dronkers 2009; Hener et al. 2012). ${ }^{1}$ Yet, since it is known that political socialization during childhood and adolescence affects participation later in life (Beck and Jennings 1982; Hener et al. 2012) it is crucial to understand how parental separation, which many young adults experience in contemporary societies, affects political and civic engagement. Moreover, as levels of participation decrease among younger generations (BFS 2008b; Blais et al. 2004; Wattenberg 2007) studying potential explanations for young adults' engagement merits empirical attention.

In sum, the two related research questions motivating our study are:

1. Descriptive: To what extent is parental separation associated with young people's participation in politics and civic life?

2. Explanatory: How can differences in levels of participation in politics and civic life between children who experienced parental separation and those who did not be explained?

Taking insights from the social learning and parental status theory, we argue that children who experienced parental separation will be less likely to participate. In brief, we will contend that parental separation reduces opportunities for social learning. Not only is there less opportunity to discuss politics at home because of the absence of one of the parents (Sandell and Plutzer 2005), separated parents are also less likely to engage in public life compared with married parents (Stoker and Jennings 1995; Voorpostel and Coffé 2012). Hence, young adults with separated parents are less likely to have a parental "role model" when it comes to public engagement. In light of the parental status theory, we contend that as divorce is related to lower levels of socioeconomic status (Peterson 1996; Poortman 2000; Aassve et al. 2007), parental separation is likely to limit young adults' resources to participate.

1 Throughout the text we use the word separation to refer to both divorce and separation (also after unmarried cohabitation). 
We study the relationship between parental divorce and political and civic participation in Switzerland. Switzerland is characterized by a high standard of living (OECD), relatively high levels of civic participation and informal helping (Purdam and Tranmer 2012; BFS 2011; Helmig et al. 2011), yet with low levels of voter turnout (Lutz 2012; OECD). It is especially interesting to assess influences on political and civic participation, because Switzerland is characterized by a high level of direct democracy in which citizens directly decide on several issues through referenda. Another argument to study this question in the Swiss context is that Switzerland's divorce rates are among the highest in Europe, and in about half of the divorces children are involved (BFS 2008a; Eurostat 2011).

We draw on data from the Swiss Household Panel (1999-2009) which offer longitudinal information gathered directly from both parents and young adults. The data also enable us to look at two forms of participation: voting frequency in referenda and volunteering. Hence, our study includes measures of both civic and political participation.

\section{Theory and Hypotheses}

\subsection{Parents and Young adults' Political and Civic Participation}

Two related explanations have been offered and empirically confirmed for the role of the parents on young adults' levels of civic and political participation: social learning and parental status. The social learning theory suggests that children are influenced by their parents through a process of social learning. It holds that young people learn from their parents about the world, how they fit into it, and how they should behave in it (Dalton 1980; Jennings and Niemi 1968; Jennings et al. 2009; Plutzer 2002; Verba et al. 2005). In addition, parents' own behaviour, including their participation in politics and in the community, functions as an example for their offspring (Bengtson et al. 2002). By participating themselves, parents communicate to their offspring that being active in politics or in the community is valued behaviour (Bekkers 2007). Furthermore, they provide their children with relevant knowledge about participation, and political and civic involvement is more likely to be discussed at home when it is actually practiced.

Besides their levels of participation, parents' socioeconomic status has been suggested to play an important role in their offspring's behaviour. Parents' socioeconomic status is associated with material and immaterial resources that stimulate or impede participation. Money has been found to be one of the prime resources for investment in political participation and voluntary work (Brady et al. 1995; Verba et al. 1995). A higher income allows more spending, is associated with the social skills that make it comfortable to do voluntary work and has a positive effect on the likelihood to be asked to volunteer (Wilson and Musick 1998). Similarly, education is known to be an important resource for political and civic participation. Higher educated citizens tend to be more politically interested and knowledgeable about politics compared with lower educated citizens who are generally more disengaged from politics (Prokic and Dronkers 2009). Wilson and Musick (1998) also indicate how education strongly and positively affects the likelihood to volunteer. Hence, children growing up in families with higher educated and wealthier parents will have more of the resources at their disposal which are known to relate to political and civic engagement. Moreover, since resources such as money and education are positively related to participation, those parents possessing them will be more likely to engage in politics and civic life and are as such-as suggested by the social learning theory-a positive civic role model for the children. Lastly, it has been shown that higher educated parents spend more 
time with their children. They also invest more time in teaching children, and in activities that stimulate their cognitive development (Bianchi and Robinson 1997). Hence, higher educated parents may be expected to invest more time in transferring their-already stronger-political competencies and engagement to their children compared with lower educated parents.

A recent study of Humphries et al. (2013) which relies on U.S. data confirms that parental education is a positive and significant predictor of voter registration and voting among young adults, in particular among white children of native-born parents. Similarly, Neundorf et al. (2013) revealed a significant positive effect of father's levels of education on young adults interest in politics among their German sample.

In sum then, young adults who grow up in families with active parents and with parents with higher socioeconomic status are more likely to be engaged politically and be active in civic associations compared with young adults growing up in families with parents who do not participate in public life and with lower levels of socioeconomic status.

\subsection{The Effect of Parental Separation on Young Adults' Political and Civic Participation}

Parental separation and divorce is a major event affecting young adults' lives and has been empirically associated with a variety of negative effects, amongst others on health and educational attainment (Amato 2000; Amato and Keith 1991; Astone and McLanahan 1991; Gahler and Garriga 2012; Havermans et al. 2014; Amato 2010). Less is known, however, about the effect of parental separation on political and civic engagement, and the scant available research shows mixed results. Sandell and Plutzer (2005) found a substantial effect of parental separation on young adults' voting turnout in the US among whites, but found no impact among racial minority groups. In their comparative study of 17 countries, Prokic and Dronkers (2009) found that being raised in a single father family had no substantial effect on civic participation in most countries (including Switzerland). They found higher levels of civic participation in single-mother families compared with twoparent families in Switzerland and three other countries, and no relationship at all in the other European countries and the U.S. By contrast, Dolan (1995) revealed that the absence of a father or stepfather, either through divorce or death, negatively affected levels of political trust in the U.S. Yet, an absent father had no substantial impact on young adults' levels of political participation, knowledge and efficacy. Langton (1969) showed that children growing up in maternal families in Jamaica had lower levels of political efficacy and trust compared with those raised in two-parent families. Relying on longitudinal data from Germany, Hener et al. (2012) revealed a negative relationship between growing up in a non-intact family and children's civic, social and political engagement as adults. They also demonstrated that the duration of time spent in a non-intact family as a child had a negative effect on participation as a young adult.

Based on the social learning and parental status theories presented above, we anticipate that parental separation will relate negatively to young adults' civic and political engagement. First, parental separation may reduce offspring's participation through diminishing opportunities for social learning. Voorpostel and Coffé (2012) suggest that parents decrease their own levels of political and civic participation following separation. Similarly, Stoker and Jennings (1995) argue that, particularly in the short run, divorce results in less stability in one's personal life and less attention to political affairs as personal preoccupations take hold. Furthermore, an American study by Kalil et al. (2014) looking at the time investment of different caregivers across various family structures 
revealed that children living with two resident biological caregivers receive most time investment. Finally, it is known that separated people have higher levels of residential mobility (Speare and Goldscheider 1987), and such mobility has a profound negative impact on connections with the community, civic engagement and turnout (Squire et al. 1987). In addition, a move following a divorce is often to a significantly poorer neighborhood, and turnout as well as membership in civic and other voluntary organizations is generally lower in poorer neighborhoods (Wuthnow 1998; OECD; Cohen and Dawson 1993).

In sum, adolescents who are raised by separated parents are less likely to have a positive civic and political role model and will thus be less likely to engage themselves. Moreover, children raised in separated families have fewer opportunities to discuss politics at home because of the absence of one of the parents (Sandell and Plutzer 2005), and there is ample evidence that such discussions increase young adults' levels of participation (Brady et al. 1995; Verba et al. 2005).

In addition to the social learning theory, the parental status theory may also be relevant to explain the effect of parental separation on young adults' level of engagement. Separation is generally accompanied by a decline in financial resources (Peterson 1996; Poortman 2000; McManus and DiPrete 2001; Aassve et al. 2007), potentially limiting the resources available for their children's participation (Havermans et al. 2014). Furthermore, and even though research is not conclusive, there is some evidence that married couples who are more highly educated are less likely to divorce than less-educated couples (Jalovaara 2003; Tzeng and Mare 1995; Amato 2010). In sum then, because the socioeconomic position of separated families tends to be lower, children raised in such families tend to have access to fewer resources for participation, which is likely to affect their political and civic engagement. In addition, and related to the social learning theory, the children of parents with a higher socioeconomic status are more likely to have a positive civic role model compared with the children of parents with a lower socioeconomic status. As separated parents tend to have a lower socioeconomic status compared with married parents, children raised in divorced families are less likely to have positive political and civic role models, further confirming our expectation that the anticipated negative effect of parental separation can be explained by parents' socioeconomic status.

To summarize, our hypotheses are as follows:

\subsubsection{Descriptive Research Question}

Hypothesis 1 Children with separated parents display lower levels of voting and volunteering compared with children with non-separated parents.

\subsubsection{Explanatory Research Question}

Hypothesis 2 (Social Learning Theory) The lower levels of voting and volunteering among children with separated parents compared with children with non-separated parents can be (partly) explained by separated parents' lower levels of voting and volunteering compared with non-separated parents.

Hypothesis 3 (Parental Status Theory) The lower levels of voting and volunteering among children with separated parents compared with children with non-separated parents can be (partly) explained by separated parents' lower socioeconomic status and educational level compared with non-separated parents. 


\section{Data and Measurement}

\subsection{Data}

The hypotheses presented above were tested using data from the Swiss household panel (SHP). The SHP is an ongoing yearly CATI panel study that started in 1999, and follows a randomly selected sample of households in Switzerland over time. Respondents are interviewed annually. Because the SHP collects data from all household members directly and includes questions about political and civic participation, it is especially well suited for examining the intergenerational transmission of such behaviour. Most studies on socialization rely on family-level estimates obtained from young respondents or on retrospective questions among adult respondents, and no information is available directly from the parents. In the present study, however, we can rely on first-hand information and thus include the parents' own answers regarding their political participation. Moreover, panel data allow us to follow respondents over time and look at trends in participation.

We used data from 1999 to 2009, as these waves contain our variables of interest. ${ }^{2}$ We selected for each wave all respondents aged 18-26 of whom at least one parent responded, yielding 6,191 observations coming from 2,125 individuals. Although we would have preferred to follow children while their parents go through divorce or separation, this group was too small (360 observations from 97 respondents). It is likely that respondents are less interested in participating in a survey during the process of separation. Moreover, separation is a life event that is related to moving, and sample members who move are harder to locate (Lepkowski and Couper 2002; Stoop 2005). Hence, we focused the analysis on the group of respondents whose parents were still together (married or cohabiting) or whose parents had separated before they entered the panel and who had not (yet) repartnered. ${ }^{3}$ Our final analytical sample size is 5,134 observations from 1,788 respondents and their mothers and on 3,768 observations from 1,331 respondents and their fathers. As not all respondents in the sample have the right to vote (e.g. non-Swiss residents), the analytical sample for the dependent variable frequency of voting is somewhat smaller with 4,579 observations from 1,601 respondents and their mothers and 3,311 observations from 1,180 respondents and their fathers. ${ }^{4}$

\subsection{Dependent Variables}

We considered two different types of participation: (1) frequency of voting in referenda and (2) whether or not the respondent was involved in volunteering activities. Voting

\footnotetext{
2 The original sample of all household members in 1999 contained 7,788 individuals (from 5,074 households). In $200961.6 \%$ (4,800 individuals from 2,718 households) of the original sample were still in the panel. In 2004 a refresher sample of 3,654 individuals started (from 2,538 households). Of this refresher sample $63.2 \%$ (2,309 individuals from 1,475 households) were still successfully followed in 2009. In total, there were 7,109 individuals living in 4,406 households still in the sample in 2009. The survey included new household members entering the household in the sample and individuals leaving the household remained in the sample as well. Studies on the quality of the SHP data indicated that attrition in the SHP was relatively high, yet non-response bias was mild, and comparable to other large household panel studies (Lipps 2007; Voorpostel 2010).

${ }^{3}$ From the respondents whose parents separated while in the panel we only kept the observations after the parental separation. We disregarded parents who were widowed.

4 As is common in surveys, participation in the SHP is higher among women than men. Men are also somewhat more likely to drop out of panel studies than women (Voorpostel 2010; Stoop 2005) As a result, the sample for respondents and their fathers is smaller than for respondents and their mothers.
} 
frequency was measured by asking respondents: "Let's suppose there are ten federal polls in a year. How many do you usually take part in?" Responses could vary from 0 to 10 . The question thus measures respondent's participation in referenda, which is at the heart of Swiss democracy. Volunteering was measured as a dichotomous variable: "Do you have honorary or voluntary activities within an association, an organization or an institution?" Respondents could answer (1) yes or (0) no. As a measure of civic participation, volunteering refers to an active and demanding way of participation in civic life which demands different resources (including time) and skills. Descriptive statistics for all variables included in our analyses are provided in Table 1.

\subsection{Independent Variables}

Our main explanatory variable, parental separation, is measured by a dummy variable: (0) young adults' biological parents are living together, (1) young adults' biological parents have separated or divorced and live apart. ${ }^{5}$ To assess the effect of parental separation independent of the effect of living in the same household, we also included in the model whether respondents lived in the same household as the parent. ${ }^{6}$

To test the hypothesis on social learning, we included mother's/father's level of voting and volunteering, which were measured in the same way as the dependent variables (see above). Mother's and father's voting frequency were centered on the mean.

As a measurement of the parental socioeconomic status we introduced the parents' level of education and occupational status. ${ }^{7}$ Mother's and father's level of education was measured in three categories: compulsory, secondary and tertiary education. The first category was the reference group. Mother's and father's occupational status was measured using the Erikson-Goldhorpe-Portocarero classification (EGP), which is based on employment status and occupation (Erikson and Goldthorpe 1992). The original scale with 11 categories was recoded into four dummy variables. The low-status group included semiand unskilled manual employees, farm labor and self-employed farmers. The medium status group contained self-employed with and without employees, manual supervisors, skilled manual employees and routine non-manual employees. The high-status group included higher controllers and low controllers. The group for which occupational status was missing (for example housewives) was a fourth, separate category. The low status group functioned as the reference category.

\subsection{Control Variables}

Young adults often resemble their parents via status inheritance and a shared social milieu. Young adults whose parents are advantaged in socioeconomic terms are thus not only likely to grow up in a family with more resources and in a politically rich context. They are

\footnotetext{
5 In our sample, $16 \%(\mathrm{n}=819)$ of the mothers are separated and $4 \%(\mathrm{n}=148)$ of the fathers are separated. The vast majority of the separated parents are legally divorced: $87 \%$ of the separated mothers and $80 \%$ of the separated fathers.

6 The majority of young adults in our sample lived with their parents: $88.6 \%$ for the mother-child dyads and $89.3 \%$ for the father-child dyads. As it is harder to locate sample members after they move (Lepkowski and Couper 2002), children in this age group who moved out and no longer live with their parents are more likely to drop out compared to respondents from households where such changes did not take place. As a result, the parent-child dyads who share a household are most likely somewhat overrepresented.

7 Unfortunately we were not able to include household income. As is common in surveys, there was a high number of missing values for this variable (around $20 \%$ ).
} 
Table 1 Descriptive statistics for the sample of young adults $(\mathrm{N}=5,134)$, mothers $(\mathrm{N}=5,134)$ and fathers $(\mathrm{N}=3,768)$

\begin{tabular}{|c|c|c|c|c|c|c|c|c|}
\hline & \multirow[t]{2}{*}{ Min } & \multirow[t]{2}{*}{ Max } & \multicolumn{2}{|c|}{ Young adult } & \multicolumn{2}{|c|}{ Mother } & \multicolumn{2}{|l|}{ Father } \\
\hline & & & Mean & SD & Mean & SD & Mean & SD \\
\hline Volunteering & 0 & 1 & 0.349 & 0.477 & 0.470 & 0.499 & 0.557 & 0.497 \\
\hline Voting frequency & 0 & 10 & 7.075 & 3.241 & 7.967 & 2.817 & 8.458 & 2.352 \\
\hline Parents separated & 0 & 1 & 0.160 & 0.366 & & & & \\
\hline Living with mother & 0 & 1 & 0.886 & 0.318 & & & & \\
\hline Living with father & 0 & 1 & 0.893 & 0.309 & & & & \\
\hline Compulsory level of education & 0 & 1 & 0.363 & 0.481 & 0.169 & 0.375 & 0.059 & 0.236 \\
\hline Secondary level of education & 0 & 1 & 0.566 & 0.496 & 0.636 & 0.481 & 0.458 & 0.498 \\
\hline Tertiary level of education & 0 & 1 & 0.071 & 0.257 & 0.195 & 0.397 & 0.482 & 0.500 \\
\hline Low occupational status & 0 & 1 & 0.099 & 0.299 & 0.126 & 0.332 & 0.122 & 0.327 \\
\hline Medium occupational status & 0 & 1 & 0.363 & 0.481 & 0.334 & 0.472 & 0.222 & 0.415 \\
\hline High occupational status & 0 & 1 & 0.222 & 0.416 & 0.316 & 0.465 & 0.576 & 0.494 \\
\hline No occupational status & 0 & 1 & 0.313 & 0.464 & 0.223 & 0.416 & 0.081 & 0.272 \\
\hline In school & 0 & 1 & 0.625 & 0.484 & & & & \\
\hline Female & 0 & 1 & 0.471 & 0.499 & & & & \\
\hline Age & 18 & 26 & 21.003 & 2.415 & & & & \\
\hline Church attendance & 0 & 7 & 2.102 & 1.601 & & & & \\
\hline
\end{tabular}

For the variable voting frequency $\mathrm{N}=4,579$ for young adults, 4,579 for mothers, and 3,311 for fathers Source Swiss household panel survey (1999-2009)

also likely themselves to attain a higher socioeconomic status than young adults living with parents with less socioeconomic resources (e.g., Jennings et al. 2009; Verba et al. 2005). Moreover, it is well known that young adults' socioeconomic status has a major effect on their levels of political engagement (Quintelier and van Deth 2014). Hence, it is important to control for these socioeconomic characteristics of the young adults. Educational level was operationalized in the same way as for the parents. In addition, we included a dummy for whether the child was still enrolled in school. This dummy variable reflects the institutional or social integration of the children and controls for the fact that young people's educational level at school is obviously influenced by the fact that they are still completing their education. We also control for the occupational status of the children, with a similar measurement as for the parents. Moreover, as church attendance has been found to be positively related to political and civic participation (Bekkers 2007; Aassve et al. 2007), we included frequency of church visits of the children, which is measured from (0) never to (7) several times a week. Finally, we included age as a continuous variable (recoded so that 0 refers to 18 years old) and gender (with the value zero for male and one for female respondents) as control variables.

\subsection{Analytical Strategy}

Since our data consist of multiple observations over time for each respondent, we have to take the clustered structure of the data into account in our analyses. For this purpose, we applied a multilevel model with observations (Level 1) nested within individuals (Level 2), and with a random slope for time (age) (Snijders and Bosker 1999; Singer and Willett 
2003). ${ }^{8,9}$ As voting frequency is a continuous dependent variable, we estimated multilevel OLS regression models. Multilevel logistic regression models were run for volunteering, which is a dummy variable. ${ }^{10}$

Since the data often only included information from either the mother or the father for the group of respondents with separated parents, we estimated the models for mothers and fathers separately. We estimated four nested models for voting frequency and four models for volunteering for each dyad (mother-young adult and father-young adult). The first model (Model 1) includes our main explanatory variable, separation, and controls for a variety of young adults' characteristics (living with mother/father, age, level of education, occupational status, gender, school attendance and church attendance). In Model 2, parents' voting frequency or engagement as a volunteer is added. Hence this model allows us to test our hypothesis on social learning and to investigate to what extent the anticipated negative effect of separation can be explained by separated parents' lower levels of political and civic engagement. In Model 3, the variables measuring parental socioeconomic status are introduced. These analyses enable us to investigate to what extent differences in socioeconomic status between separated and non-separated parents can explain the expected negative effect of separation on young adults' political and civic participation. Model 4 is the most complete, and includes both parental participation and parental socioeconomic status.

\section{Results}

\subsection{Voting Frequency}

Looking at the analyses investigating young adults' voting frequency (Table 2), the first model indicates in line with our expectation (Hypothesis 1) that parental separation has a negative effect on young adults' levels of voting frequency. Young adults whose mother and father do no longer live together vote close to one out of ten times less in referenda compared with young adults whose parents are living together. ${ }^{11}$ Living with mother or father is positively associated with voting frequency, an effect that remains stable over all models.

Model 2 introduces parents' voting frequency and allows us to test the social learning hypothesis. The analysis reveals that the coefficient of parental separation is substantially smaller compared with the first model, in particular in the analyses for the mothers. This indicates that a significant part of the negative effect of parental separation can be explained by the parents' voting frequency. The latter also has a significant and positive effect on young adults' voting frequency. In sum then, our analyses seem to support the

\footnotetext{
${ }^{8}$ Preliminary analyses indicated that the variance on the family level was not significant in most models (the group sizes are small, and many families have only one adult child in the data). Hence, we present the more parsimonious two-level models.

${ }^{9}$ Given the limited number of respondents who experience parental separation while in the study, we were unable to pursue the alternative analytical strategy of fixed effects models.

${ }^{10}$ We assessed the statistical reliability of the models and found that the models were stable. Examination of the residuals assured us that there were no strong violations of the model assumptions.

11 Note that the number of respondents with separated fathers is relatively small $(\mathrm{n}=142$ for voting frequency, and $\mathrm{n}=148$ for volunteering) which may explain why on the overall the effect of separation is less significant for the analyses (for both voting frequency and volunteering) looking at fathers compared with those focusing on the mother-young adults dyads.
} 


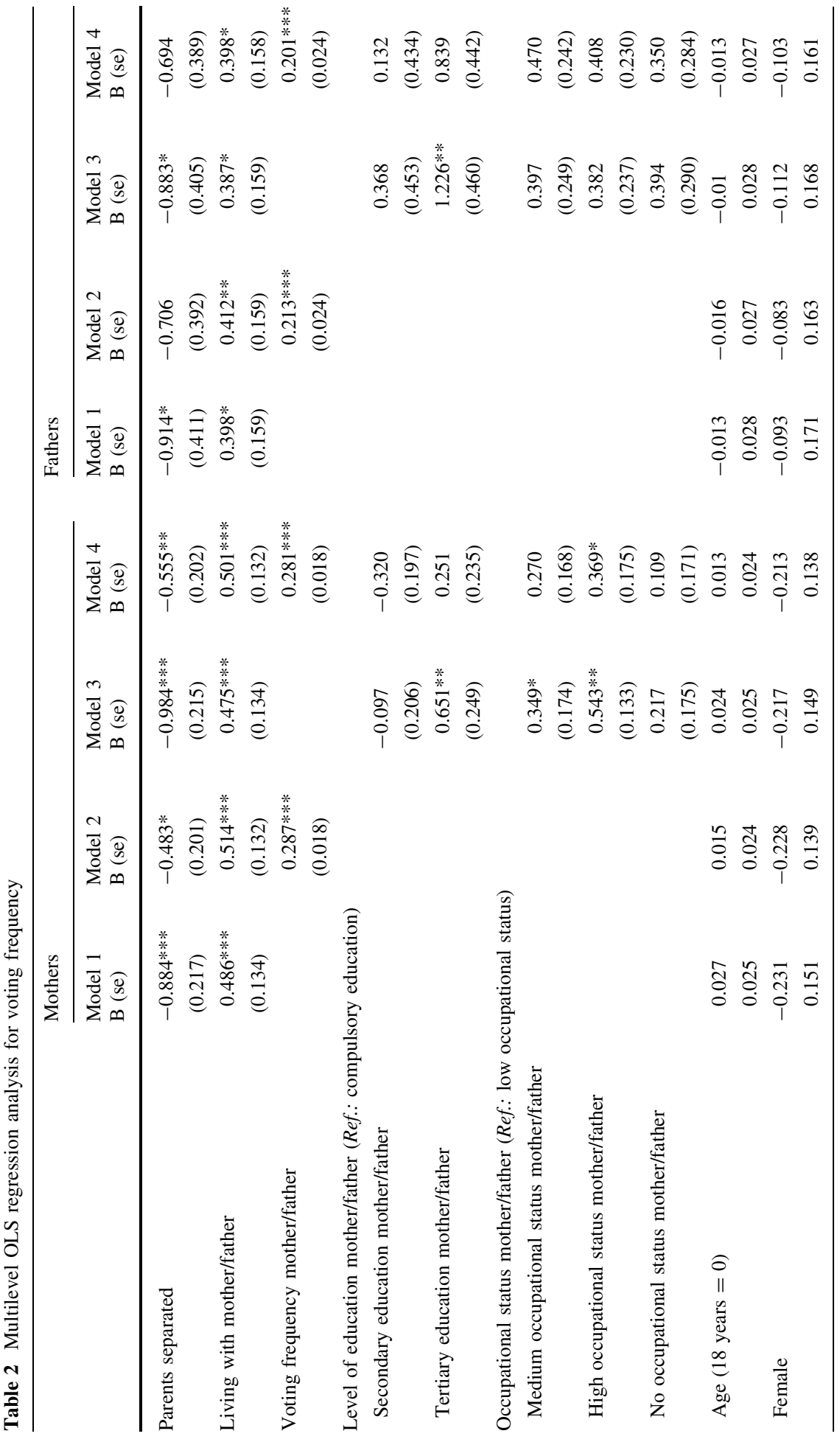




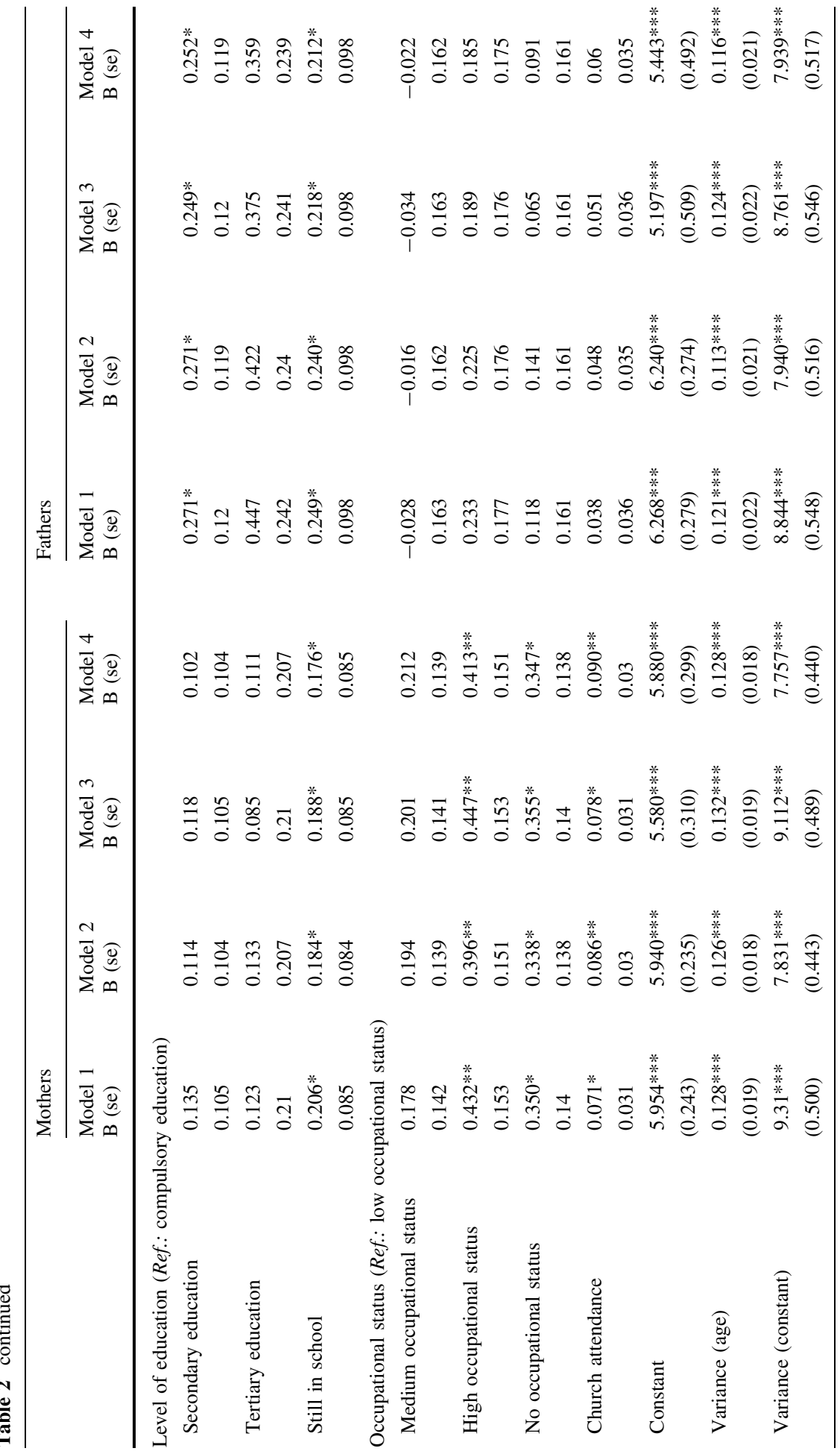




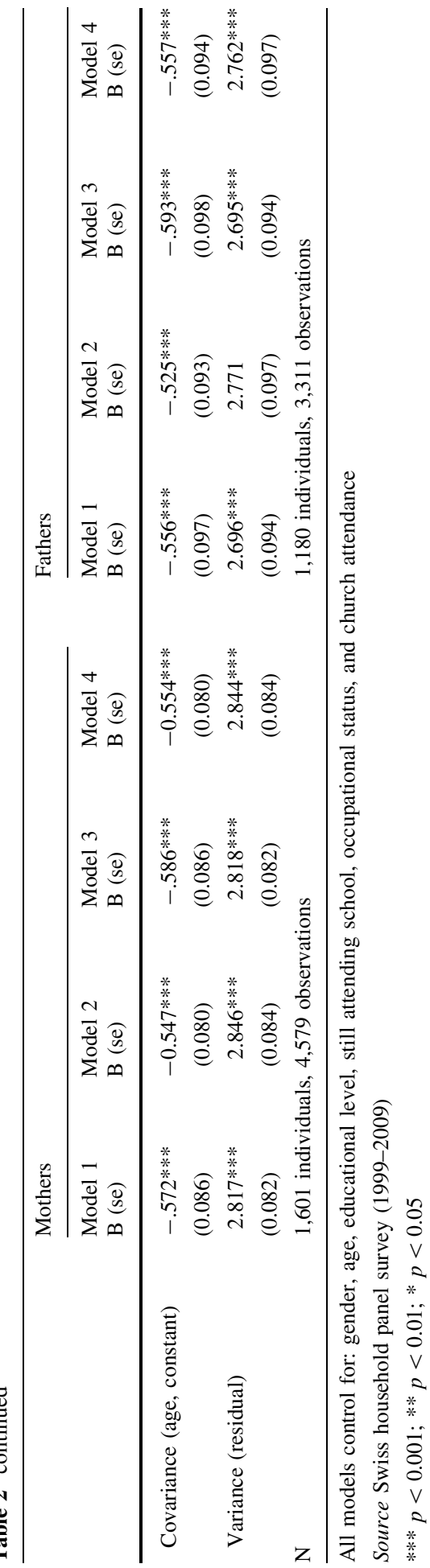


social learning theory (Hypothesis 2). They demonstrate that because separated parents are less likely to vote, their children are also less likely to participate in referenda compared with young adults with parents who are still living together.

Model 3 introduces parents' socioeconomic status and enables us to investigate to what extent status can explain the negative effect of parental separation on young adults' voting frequency. Since the coefficients of parental separation do not differ substantially between Models 1 and Models 3, our analyses do not seem to support the parental status theory (Hypothesis 3). Yet, parents' socioeconomic status does affect young adults' voting frequency. In particular, young adults with tertiary educated parents and with parents with a high occupational status increase their voting frequency by 0.651 and 0.534 respectively compared with young adults with parents who are lower educated and have low occupational status.

The final model (Model 4) includes simultaneously parents' voting frequency and socioeconomic status. It shows-for both the analyses with mother and father-that the effect of parental voting frequency on young adults' participation in referenda remains substantial and positive. Yet, the effect of socioeconomic status (tertiary level of education in both the mother-young adults and father-young adults analyses, and medium and higher occupational status in the mother-young adults analyses) decreases substantially. This indicates that the effect of parents' socioeconomic status on young adults' voting frequency can be mainly explained by parents' voting frequency. In the mothers-young adults analysis, the negative effect of separation is still statistically significant, though less strong than in the first model. In the fathers-young adults analysis, the effect of separation is (similar to Model 2) no longer significant.

To illustrate the effect of parental separation on young adults' voting frequency, Fig. 1a, b show the predicted frequency of voting by parental separation based on Model 4 for mothers (Fig. 1a) and fathers (Fig. 1b). Both figures show a clear difference in the predicted participation by parental separation. When parents are not separated, young adults vote 7.1 times on average (Fig. 1a, b), when parents are separated this figure drops to 6.1 (Fig. 1a) and 6.0 (Fig. 1b) respectively.

\subsection{Volunteering}

Having established the effect of parental separation on young adults' voting frequency, we now turn to our test of the effect of separation on young adults' likelihood to volunteer (Table 3).

In line with our hypothesis (Hypothesis 1) and similar to the analysis investigating voting frequency, the first model focusing on mother-young adult dyads reveals a negative effect of separation on volunteering. The odds ratio $\left(\mathrm{e}^{-0.062}\right)$ is 0.939 , indicating a $7 \%$ lower likelihood of volunteering for children from separated parents. The effect of separation is, however, not significant when looking at father-young adult dyads.

The second model shows that mother's levels of volunteering has a positive and significant effect on young adults' level of volunteering, and explains a modest part of the effect of mother's separation on young adults' level of volunteering (the odds ratio is $\mathrm{e}^{0.078}=1.08$ ). The coefficient of the variable measuring separation decreases and ceases to be significant once mother's level of volunteering is added, supporting our second hypothesis.

The third model in Table 2, which introduces parents' socioeconomic status, demonstrates that young adults with mothers who have attained a secondary level of education are significantly more likely to volunteer compared with young adults whose mothers have 

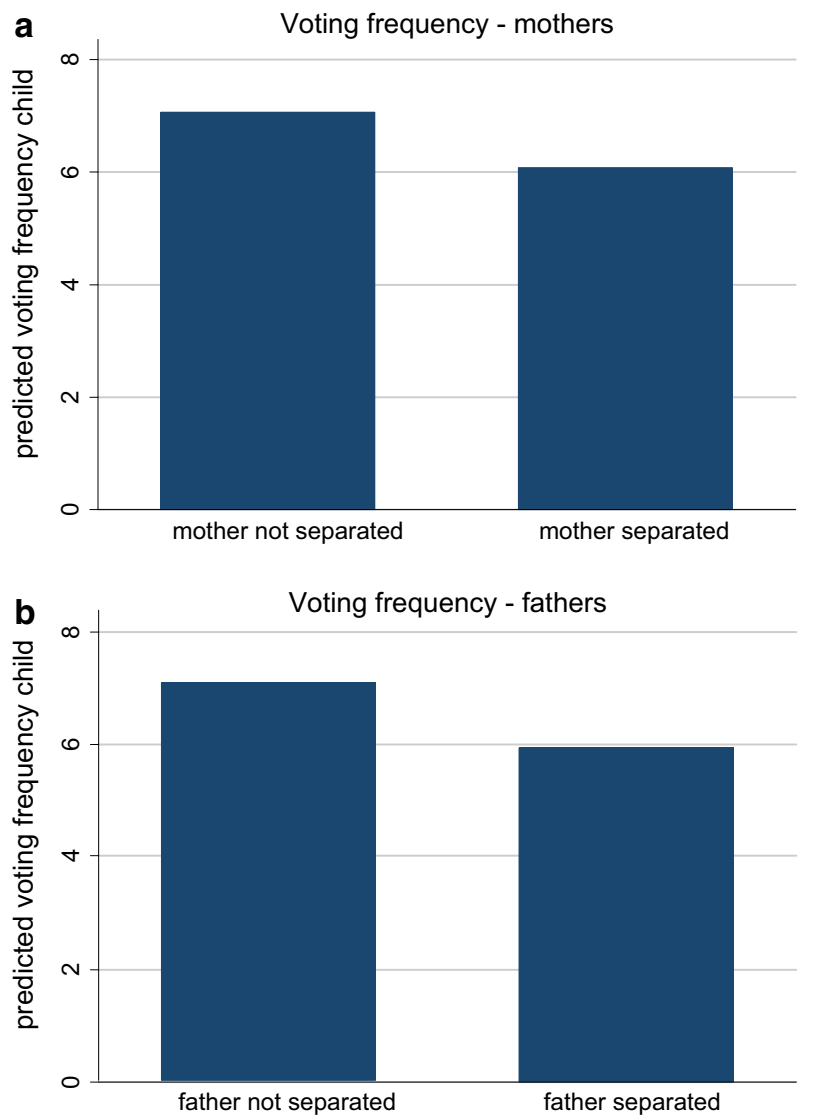

Fig. 1 a Predicted frequency of voting by parental separation [based on Model 4 (Table 2) for motherchild dyads]. b Predicted frequency of voting by parental separation [based on Model 4 (Table 2) for fatherchild dyads]. Source Swiss household panel survey (1999-2009)

attained a compulsory level of education. Yet, the coefficient of separation does not differ significantly between Model 1 and Model 3, indicating that mother's socioeconomic status does not seem to explain why young adults with a separated mother are less likely to volunteer compared with young adults whose mother is still living together with their father.

Turning to the final model which includes simultaneously parents' patterns of volunteering and socioeconomic status, the analyses reveal that the effect of separation remains not significant in the analyses for the father-young adults dyad. In the analysis focusing on the effect of mother's characteristics on young adults' engagement as a volunteer, we find that the experience of a separation has a minor negative effect. Thus whereas the effect of separation was not significant in the second model in which we only introduced mother's level of volunteering, it is again slightly significant when both mother's volunteering and socioeconomic status are controlled for.

To get an indication of the magnitude of the effect of parental separation on volunteering after taking all other variables into account, Fig. $2 \mathrm{a}, \mathrm{b}$ show the predicted 


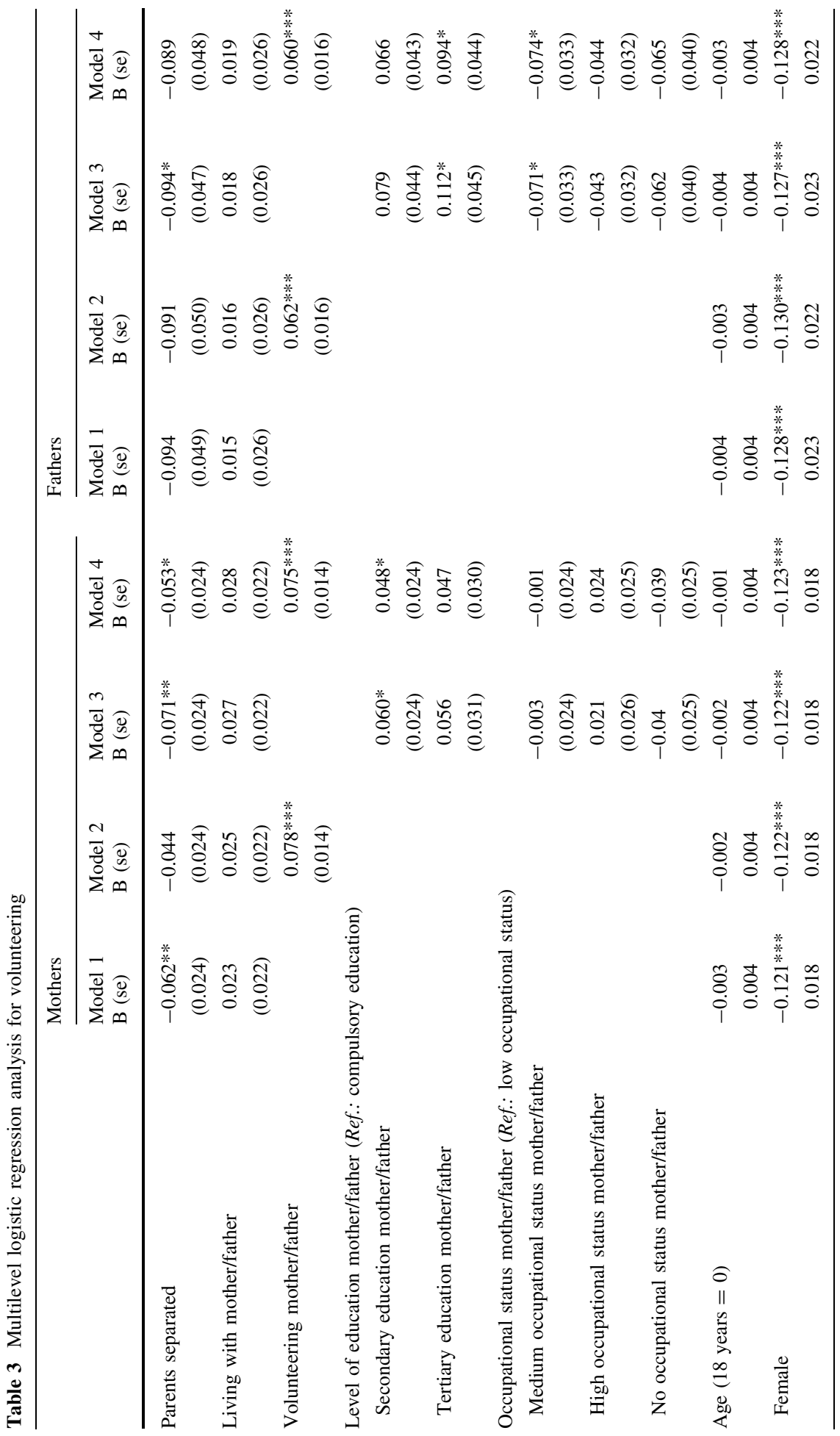




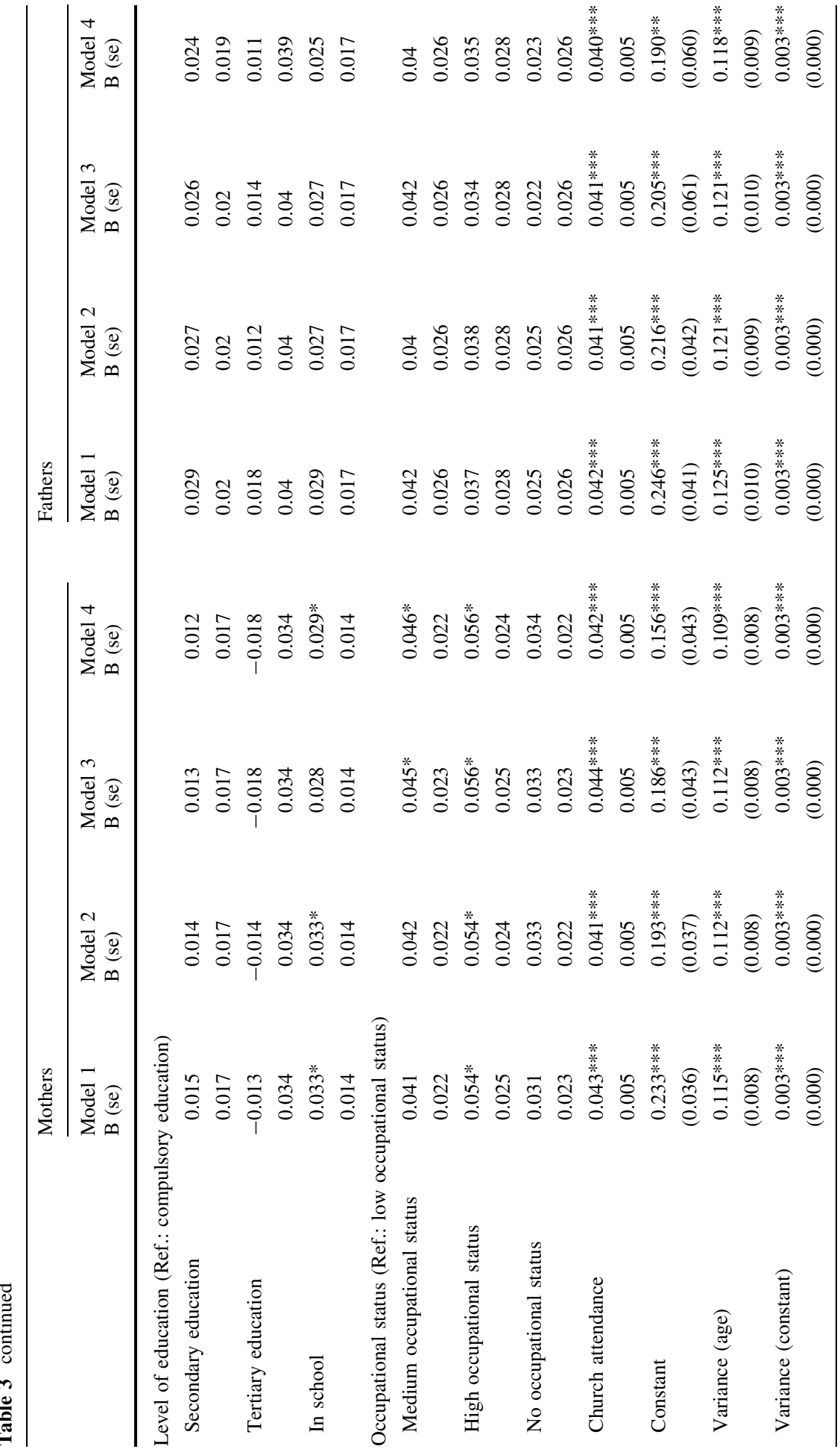




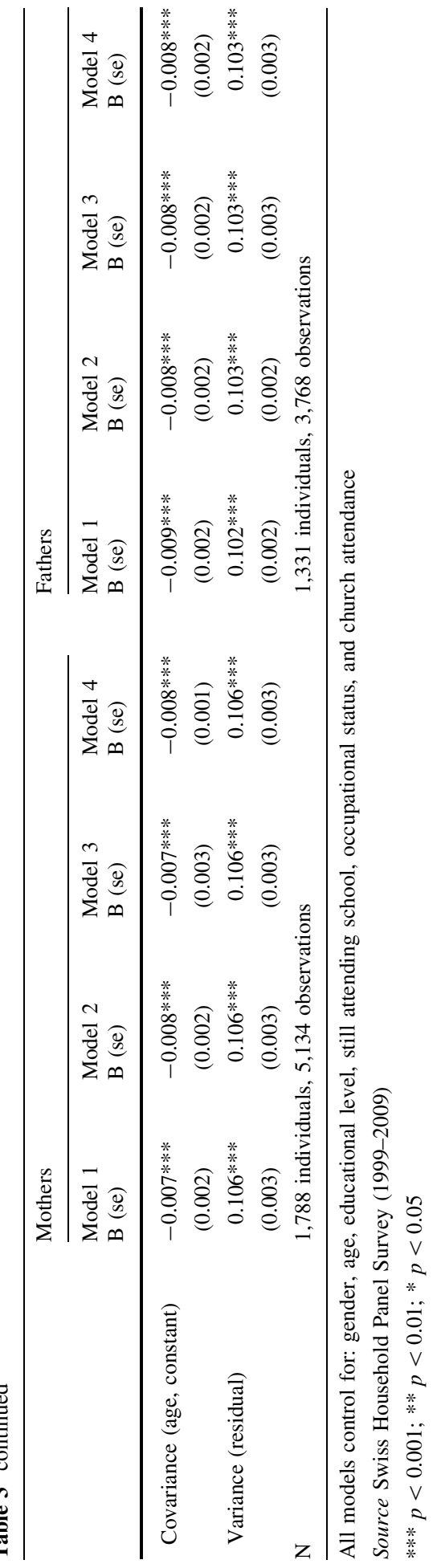



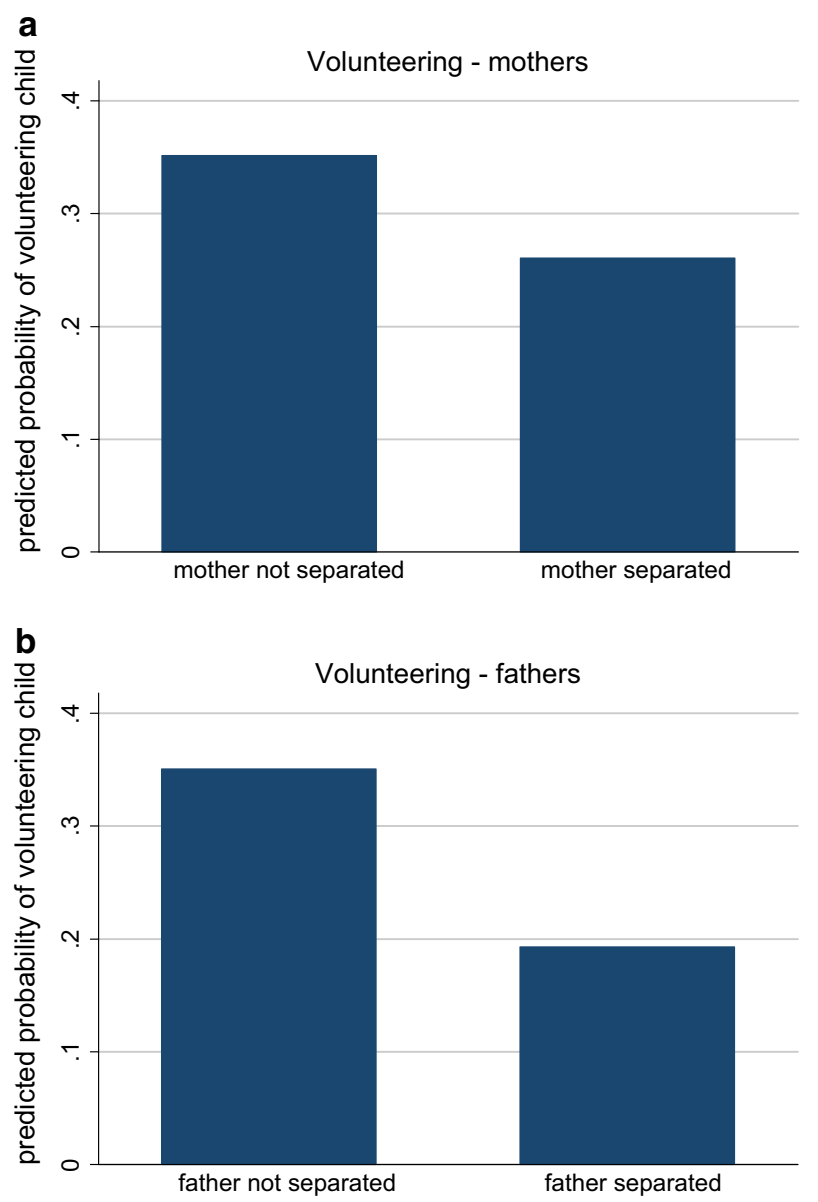

Fig. 2 a Predicted probability of volunteering by parental separation [based on Model 4 (Table 3) for mother-child dyads]. b Predicted probability of volunteering by parental separation [based on Model 4 (Table 3) for father-child dyads]. Source Swiss household panel survey (1999-2009)

probability of volunteering based on Models 4 for the mother-child dyad (Fig. 2a) and the father-child dyad (Fig. 2b). The figures demonstrate an identical probability of 0.35 for the group whose parents are together. For the group whose parents are separated the predicted probability is lower: 0.26 for the models based on the mother-child dyad and 0.19 for the models based on the father-child dyad.

\section{Conclusion}

As the number of young adults growing up within separated families has increased substantially during the last few decades, an extensive literature on the effect of separation on young adults' wellbeing, health and educational attainment has emerged (Amato 2000; Kalmijn 2010; Amato 2010). Little research has however looked at the effect of separation on young adults' political and civic engagement. While it is well known that parents have a 
major influence on young adults' political attitudes and behaviour (Coffé and Voorpostel 2010; Flanagan et al. 1998; Flanagan and Sherrod 1998; Jennings et al. 2009; Kroh 2011; Nieuwbeerta and Wittebrood 1995; Perry and Associates 2002; Verba et al. 2005; Wernli 2007), these studies have been mainly conducted within traditional families, and the question to what extent parental separation affects young adults' levels of civic and political participation remains hitherto underexplored.

Using data from the Swiss Household Panel Survey (1999-2009), our study offers a systematic examination of the effect of separation on young adults' voting frequency and engagement as a volunteer. As such, we believe it offers an important step in providing a richer analysis of family socialization and political and civic engagement. In brief, our analyses reveal that having separated parents generally negatively affects young adults' political and civic engagement. Young adults with separated parents are substantially less likely to vote frequently and to engage as a volunteer compared with young adults whose parents are living together. This result confirms the major consequence separation has on young adults' lives as shown in previous research looking at various outcomes, including young adults' health and wellbeing, educational attainment and psychological adjustment (Amato 2000, 2010; Kalmijn 2010; Amato and James 2010; Amato and Keith 1991; Gahler and Garriga 2012). Our conclusion also corroborates the main findings of some previous studies (Hener et al. 2012; Sandell and Plutzer 2005; Dolan 1995) which revealed a negative link between parental separation and political engagement (e.g., voting) and attitudes (e.g., political efficacy and trust). It stands, however, in contrast to findings of Prokic and Dronkers (2009). Using data from the 1999 Civic Education Study, they found that children living in single-mother-families had significant higher levels of civic participation than children in two-parent families in Switzerland. Their analyses revealed no substantial difference in the level of civic engagement between children living in singlefather families and children living in two-parent families. Perhaps the negative effect of separation only becomes clear when children grow older and establish themselves in the political and civic arena.

Trying to explain this negative effect of parental separation, our analyses lent more support to the social learning theory than to the parental status theory. In particular, lower levels of engagement among separated parents seem to (at least partly) explain the negative effect of parental separation on young adults' participatory patterns. As separated parents themselves engage less in political and civic life, young adults do not have the example of engaged parents to the same extent as young adults growing up with parents who are living together. Such lack of examples seems to negatively affect young adults' own engagement. Differences in socioeconomic status between separated and not-separated parents do not seem to convincingly explain lower levels of civic and political participation among young adults with separated parents. In fact, our analyses revealed the relatively limited effect of parental level of socioeconomic status beyond their pattern of political participation, indicating that what parents $d o$ in terms of political participation is more important than who they are.

Future research could further develop our understanding of the effect of parental separation on young adults' civic and political participation in different useful ways. First, due to limited data, we took a static approach and investigated the difference in political and civic participation between young adults whose parents are separated and those whose parents are not separated. Further research could take a more dynamic approach and follow young adults over time to explore the effect of parental separation in the short and long term. In their study on Germany, Hener et al. (2012) assessed the duration of living in a non-intact family and revealed that "civic education decreases with the duration spent in a 
non-intact family during childhood" (p. 16). Clarifying this mechanism through following young adults' participation in civic and political life through and after parental divorce, merits further attention. As young adults settle into their new family situation, their civic and political participation may no longer be distinguishable from the participatory patterns of young adults who grew up with both parents.

A second avenue for further research could be to explore other theories and explanations for the effect of parental separation than those considered in the current study. One such explanation could be geographical relocation. Parental separation often goes together with relocation, which may weaken ties with the local community and thus decrease young adults' levels of engagement.

Finally, previous research on the effect of parental separation on various outcomes (including health and wellbeing, educational attainment or psychological adjustment), has been conducted in a variety of countries and showed a consistent negative effect of separation. Hence, it seems reasonable to expect that the negative link we revealed within our Swiss sample between parental separation and young adults' political and civic engagement will also hold in other countries. Yet, further research could usefully explore to what extent our findings also hold outside of Switzerland.

For now, we believe we may conclude that our study has contributed to the literature on political family socialization by indicating a notable effect of parental separation on young adults' level of civic and political engagement. As a substantial number of young adults grow up in separated families in contemporary societies, investigating the effect of parental separation deserves our scholarly attention.

Acknowledgments The authors are grateful to Laura Stoker for her valuable suggestions and the fruitful discussions. They would also like to thank Harry Chapman for his editorial help. This study uses data from the Swiss Household Panel (SHP), which is based at the Swiss Centre of Expertise in the Social Sciences FORS. The SHP is financed by the Swiss National Science Foundation (SNSF).

\section{References}

Aassve, A., Betti, G., Mazzuco, S., \& Mencarini, L. (2007). Marital disruption and economic well-being: A comparative analysis. Journal of the Royal Statistical Society: Series A (Statistics in Society), 170(3), 781-799. doi:10.1111/j.1467-985X.2007.00483.x.

Amato, P. R. (2000). The consequences of divorce for adults and children. Journal of Marriage and the Family, 62, 1269-1287.

Amato, P. R. (2010). Research on divorce: Continuing trends and new developments. Journal of Marriage and Family, 72(3), 650-666. doi:10.1111/j.1741-3737.2010.00723.x.

Amato, P. R., \& James, S. (2010). Divorce in Europe and the United States: Commonalities and differences across nations. Family Science, 1(1), 2-13. doi:10.1080/19424620903381583.

Amato, P. R., \& Keith, B. (1991). Parental divorce and adult well-being: A meta-analysis. Journal of Marriage and the Family, 53, 43-58.

Andolina, M. W., Jenkins, K., Zukin, C., \& Keeter, S. (2003). Habits from home, lessons from school: Influences on youth civic engagement. PS: Political Science and Politics, 36(2), 275-280.

Astone, N. M., \& McLanahan, S. S. (1991). Family structure, parental practices and high school completion. American Sociological Review, 56(3), 309-320. doi:10.2307/2096106.

Beck, P. A., \& Jennings, M. K. (1982). Pathways to participation. The American Political Science Review, 76(1), 94-108. doi:10.2307/1960445.

Bekkers, R. (2007). Intergenerational transmission of volunteering. Acta Sociologica, 50(2), 99-114.

Bengtson, V. L., Biblarz, T. J., \& Roberts, R. E. (2002). How families still matter: A longitudinal study of youth in two generations. Cambridge: Cambridge University Press.

BFS. (2008a). Familien in der Schweiz: Statistischer Bericht 2008. Neuchâtel: BFS.

BFS. (2008b). Freiwilligenarbeit in der Schweiz. Neuchâtel: BFS.

BFS. (2011). Freiwilligenarbeit in der Schweiz 2010. Neuchâtel: BFS. 
Bianchi, S. M., \& Robinson, J. (1997). What did you do today? Children's use of time, family composition, and the acquisition of social capital. Journal of Marriage and Family, 59(2), 332-344.

Blais, A., Gidengil, E., Nevitte, N., \& Nadeau, R. (2004). Where does turnout decline come from? European Journal of Political Research, 43, 221-236.

Brady, H. E., Verba, S., \& Schlozman, K. L. (1995). Beyond Ses: A resource model of political participation. The American Political Science Review, 89(2), 271-294. doi:10.2307/2082425.

Coffé, H., \& Voorpostel, M. (2010). Young people, parents and radical right voting: The case of the Swiss people's party. Electoral Studies, 29, 435-443.

Cohen, C., \& Dawson, M. (1993). Neighborhood poverty and African-American politics. American Political Science Review, 95, 589-602.

Dalton, R. J. (1980). Reassessing parental socialization: Indicator unreliability versus generational transfer. American Political Science Review, 74, 421-431.

Dolan, K. (1995). Attitudes, behaviors, and the influence of the family: A reexamination of the role of family structure. Political Behavior, 17(3), 251-264. doi:10.2307/586521.

Erikson, R., \& Goldthorpe, J. H. (1992). The constant flux: A study of class mobility in industrial societies. Oxford: Clarendon.

Eurostat. (2011). Marriage and divorce statistics. http://epp.eurostat.ec.europa.eu/statistics_explained/ index.php/Marriage_and_divorce_statistics. Accessed 1 May 2012.

Flanagan, C. A., Bowes, J. M., Jonsson, B., Csapo, B., \& Sheblanova, E. (1998). Ties that bind: Correlates of adolescent's civic commitments in seven countries. Journal of Social Issues, 54(3), 457-475.

Flanagan, C. A., \& Sherrod, L. R. (1998). Youth political development: An introduction. Journal of Social Issues, 54(3), 447-456.

Gahler, M., \& Garriga, A. (2012). Has the association between parental divorce and young adults' psychological problems changed over time? Evidence from Sweden, 1968-2000. Journal of Family Issues, . doi:10.1177/0192513x12447177.

Havermans, N., Botterman, S., \& Matthijs, K. (2014). Family resources as mediators in the relation between divorce and children's school engagement. The Social Science Journal, Advance Online Publication. doi:10.1016/j.soscij.2014.04.001.

Helmig, B., Gmür, M., Bärlocher, C., Von Schnurbein, G., Degen, B., Nollert, M., et al. (2011). The Swiss civil society sector in a comparative perspective. VMI Research Series. Volume 6. Fribourg: Institute for Research on Management of Associations, Foundations and Cooperatives (VMI).

Hener, T., Rainer, H., \& Siedler, T. (2012). Political socialization in flux? Linking family non-intactness during childhood to adult civic engagement. CESifo Working Paper No. 3918. Munich: CESifo.

Humphries, M., Muller, C., \& Schiller, K. S. (2013). The political socialization of adolescent children of immigrants. Social Science Quarterly, 94(5), 1261-1282. doi:10.1111/ssqu.12025.

Jalovaara, M. (2003). The joint effects of marriage partner's socioeconomic positions on the risk of divorce. Demography, 40(1), 67-81. doi:10.1353/dem.2003.0004.

Jennings, M. K., \& Niemi, R. G. (1968). The transmission of political values from parent to child. American Political Science Review, 62, 169-184.

Jennings, M. K., Stoker, L., \& Bowers, J. (2009). Politics across generations: Family transmission reexamined. The Journal of Politics, 71(3), 782-799.

Kalil, A., Ryan, R., \& Chor, E. (2014). Time investments in children across family structures. The ANNALS of the American Academy of Political and Social Science, 654(1), 150-168. doi:10.1177/ 0002716214528276.

Kalmijn, M. (2010). Country differences in the effects of divorce on well-being: The role of norms, support, and selectivity. European Sociological Review, 26(4), 475-490. doi:10.1093/esr/jcp035.

Kroh, M. (2011). Fällt der Apfel immer weiter vom Stamm? Veränderungen der intergenerationalen Stabilität von Parteibindungen. PVS Sonderheft 2011 "Wählen in Deutschland".

Langton, K. (1969). Political socialization. New York: Oxford University Press.

Lepkowski, J. M., \& Couper, M. P. (2002). Nonresponse in the second wave of longitudinal household surveys. In R. M. Groves, D. A. Dillman, J. L. Eltinge, \& R. J. Little (Eds.), Survey nonresponse. New York: Wiley.

Lipps, O. (2007). Attrition in the Swiss household panel. Methoden-Daten-Analysen, 1(1), 45-68.

Lutz, G. (2012). Elections fédérales 2011: Participation et choix électoral. Lausanne: FORS.

McManus, P. A., \& DiPrete, T. A. (2001). Losers and winners: The financial consequences of separation and divorce for men. American Sociological Review, 66(2), 246-268. doi:10.2307/2657417.

Neundorf, A., Smets, K., \& Garcia-Albacete, G. M. (2013). Homemade citizens: The development of political interest during adolescence and young adulthood. Acta Politica, 48(1), 92-116.

Nieuwbeerta, P., \& Wittebrood, K. (1995). Intergenerational transmission of political party preference in the Netherlands. Social Science Research, 24, 243-261. 
OECD. OECD better life index. http://www.oecdbetterlifeindex.org. Accessed 17 July 2014.

Perry, L. S., \& Associates. (2002). Short-term impacts, long-term opportunities: The political and civic engagement of young adults in America. http://www.civicyouth.org/research/products/National_ Youth_Survey/summary.pdf.

Peterson, R. R. (1996). A re-evaluation of the economic consequences of divorce. American Sociological Review, 61(3), 528-536. doi:10.2307/2096363.

Plutzer, E. (2002). Becoming a habitual voter: Inertia, resources, and growth in young adulthood. American Political Science Review, 96(1), 41-56.

Poortman, A.-R. (2000). Sex differences in the economic consequences of separation: A panel study of the Netherlands. European Sociological Review, 16(4), 367-383.

Prokic, T., \& Dronkers, J. (2009). Parental divorce and attitudes about society of their children. Paper presented at the seventh meeting of the European network for sociological and demographic study of divorce, Antwerp, Belgium, June 25-26.

Purdam, K., \& Tranmer, M. (2012). Helping values and civic engagement. European Societies, 14(3), 393-415.

Quintelier, E., \& van Deth, J. W. (2014). Supporting democracy: Political participation and political attitudes. Exploring causality using panel data. Political Studies, 62, 153-171. doi:10.1111/1467-9248. 12097.

Sandell, J., \& Plutzer, E. (2005). Families, divorce and voter turnout in the US. Political Behavior, 27(2), $133-162$.

Singer, J. D., \& Willett, J. B. (2003). Applied longitudinal data analysis: Modeling change and event occurrence. New York: Oxford University Press.

Snijders, T. A. B., \& Bosker, R. J. (1999). Multilevel analysis: An introduction to basic and advanced multilevel modeling. London: Sage.

Speare, A, Jr, \& Goldscheider, F. K. (1987). Effects of marital status change on residential mobility. Journal of Marriage and Family, 49(2), 455-464. doi:10.2307/352314.

Squire, P., Wolfinger, R. E., \& Glass, D. P. (1987). Residential mobility and voter turnout. The American Political Science Review, 81(1), 45-65. doi:10.2307/1960778.

Stoker, L., \& Jennings, M. K. (1995). Life-cycle transitions and political participation: The case of marriage. The American Political Science Review, 89(2), 421-433.

Stoop, I. A. L. (2005). The hunt for the last respondent: Nonresponse in sample surveys. The Hague: SCP.

Tzeng, J. M., \& Mare, R. D. (1995). Labor market and socioeconomic effects on marital stability. Social Science Research, 24(4), 329-351. doi:10.1006/ssre.1995.1013.

Verba, S., Schlozman, K. L., \& Brady, H. E. (1995). Voice and equality: Civic volunteerism in American politics. Cambridge: Harvard University Press.

Verba, S., Schlozman, K. L., \& Burns, N. (2005). Family ties: Understanding the intergenerational transmission of political participation. In A. S. Zuckerman (Ed.), The social logic of politics: Personal networks as contexts for political behavior (pp. 99-114). Philadelphia: Temple University Press.

Voorpostel, M. (2010). Attrition in the Swiss household panel by demographic characteristics and levels of social involvement. Swiss Journal of Sociology, 36(2), 359-377.

Voorpostel, M., \& Coffé, H. (2012). Transitions in partnership and parental status, gender, and political and civic participation. European Sociological Review, 28(1), 28-42.

Wattenberg, M. P. (2007). Is voting for young people?. New York: Longman.

Wernli, B. (2007). La transmission intergénérationnelle de l'orientation idéologique en Suisse dans les familles à plusieurs générations. Swiss Political Science Review, 13, 237-259.

Wilson, J., \& Musick, M. (1998). The contribution of social resources to volunteering. Social Science Quarterly (University of Texas Press), 79(4), 799-814.

Wuthnow, R. (1998). Loose connections: Joining together in America's fragmented communities. Cambridge: Harvard University Press. 